\title{
Theoretical Perspectives on International Student Identity
}

\author{
Vander Tavares ${ }^{\mathrm{a}^{*}}$ \\ ${ }^{a}$ Høgskolen i Innlandet, Norway \\ *Correspondence: vanderjuniort1@gmail.com
}

\begin{abstract}
Interest in international student identity has grown considerably over the last few years. In the context of international education, the emphasis on identity and the individual student may also be seen as an emerging response to the tendency of discussing international students and their identity-related experiences in homogenising ways. While there is considerable discussion about how international students' sense of self is affected by cultural differences in higher education, a theory of identity is not always in place. The purpose of this paper is to bring together three theoretical perspectives on identity that are designed to account for specific cultural, social, and linguistic influences on identity construction. These perspectives are examined with examples from data-based case studies. This paper identifies the unique affordances of each perspective while also highlighting their mutual role in challenging broad discourses that have unfavourably defined international student identity.
\end{abstract}

Keywords: agency, higher education, identity, international student, language

\section{INTRODUCTION}

Interest in international student identity at the individual level has grown considerably over the last few years. Examining identity at the individual level affords us the necessary opportunity to understand the multiple and complex ways in which broad sociological phenomena and experiences, such as transnationalism or discrimination, affect an international student more individually and qualitatively. Such an interest reflects a more recent trend in the social sciences in general, in which identity is explored increasingly more from a social perspective (Abdelal et al., 2006). Yet, in the context of international education, in particular, the growing emphasis on identity and the individual student may also be seen as a response to the prevailing trend of discussing international student identity in a collective light. Indeed, much critique has been presented with respect to the effects of the characterization of international students as a monolithic group. Popadiuk and Arthur (2004), for instance, have argued that "treating international students as a homogeneous group ignores issues of gender, culture, and power, and places individuals at greater risk for marginalization within our institutions of higher learning" (p. 128).

Some studies have attempted to move away from homogenising the whole population of international students by concentrating on ethnic groups. However, in matters related to identity, individual variation within ethnic groups still exists to such a significant extent that the same risk of misrepresentation and generalization remains. Studies which have explored identity-related experiences from the perspective of international students from the same ethnic group have unsurprisingly shown that no two students' experiences are meaningfully similar (Skyrme, 2007). Studying international student identity on a group

Received September 18, 2020; revised December 18, 2020; January 6, 2021; accepted January 30, 2021; electronically published May 1, 2021

Journal of Comparative \& International Higher Education

May, 2021, Vol. 13, No. 2, pp. 83-97.

DOI: $10.32674 /$ jcihe.v13i2.2949

(C) 2021 Journal of Comparative \& International Higher Education. All rights reserved. 
basis can oftentimes help identify some common or universal patterns of experience for the members of the group under consideration (Li, 2004). Nevertheless, a more context-sensitive and holistic approach can reveal how a student's understanding of self in light of a common experience may be mediated by individual characteristics and previous life experiences (Tian \& Lowe, 2009). In her research with international students in higher education, Gargano (2012) demonstrated that a common collective identity categorization, such as that of a mutual nationality, may be insufficient to help understand how some international students construct their identities in their new socio-cultural contexts.

Language and ethnicity continue to be the main basis upon which international student identity is generalized. Yet, such generalizations rarely reflect the students' own voices. When exploring the identityrelated experiences of Afro-Caribbean international students (ACIS), Malcolm and Mendoza (2014) showed that the students went through complex negotiations of ethnic and racial identities that were neglected by their peers due to incorrect assumptions that the students' experiences in such sociological regards could be equated to those of other similar groups, such as African-Americans. Some students felt frustrated when their interlocutors categorized their identities abstractly as "Caribbean" because the label obscured the rich individual variation that existed within the group with respect to identity. The authors argued that the "tendency to homogenize ACIS overlooks their experiences and development, and so their issues become essentially invisible for administrations and in the literature on student identity development" (p. 595). Similarly, in Campbell's (2017) autoethnography as an international student, Campbell had "to negotiate his Afro-Caribbean experience and identity with American labels and definitions" (p. 42) which reduced the complexity of his experiences to a common denominator embedded exclusively in the American sociocultural context.

At the same time, international students have also been strongly and traditionally associated with an identity of deficit. Monolingual and monocultural frameworks in higher education have contributed to positioning international students as individuals with disruptive and deficient abilities (Sawir et al., 2008), because such frameworks exclude knowledges and skills that may be regarded as foreign. Ryan (2011) has spoken of how instructors may resist "to change and adapt to new conditions and imperatives, seeing their role as simply educating students" (p. 637). By doing so, local knowledge remains privileged and opportunities to engage authentically in intercultural learning are lost. The emphasis on "fixing" international students' language has a direct impact on how the students see their place in the Englishspeaking academic world (Zhang, 2011). The deficit view of multilingual international students leads the academic community to focus on challenges, and consequently, to sustain discourses that frame international students as less intelligent. However, the very experience of leaving one's country to study abroad should be seen as the kind of success that can challenge these prevalent beliefs of inferior identities (Ryan \& Carroll, 2007).

These broad narratives, assumptions, and overgeneralizations regarding international students have become deeply ingrained in the international education literature. As a result, international student identity from an individual perspective remains systematically under-theorized, despite the complexity and diversity of individual lived experience which scholars have called attention to as well as the availability of widely applied theories of identity. The purpose of this paper is to briefly bring together three theoretical perspectives on identity that are contextually sensitive and designed to account for specific cultural, social, and linguistic influences on identity construction. These theoretical perspectives-construals of the self (Markus \& Kitayama, 1991), social identity theory (Hogg et al., 1995), and post-structuralist perspectives 
(Han, 2011) - are employed upon an individual data-based case study with an international student (Tavares, 2020). Each perspective focuses on a distinct process or dimension of identity development, and its respective impact can be seen in the case presented for each student's journey of identity construction and identity-related experiences. These perspectives provide a rich portrayal of identity and (together) foreground congruent themes with respect to international student identity, as will be discussed later in this paper.

The data presented in this paper originated from a case study (Creswell \& Poth, 2016) with three international students at a university in Canada (see Tavares, 2020). The objective of the case study was to explore the students' lived experiences holistically with particular attention to how the students' multiple and diverse experiences impacted their identity construction and enactment. Case studies normally focus on a small number of individuals so that a specific concern may be examined in depth (Gerring, 2007). Furthermore, research conceptualized through a case study approach explores the cases in their real-life contexts in order to understand the situated nature of meaning-making in subjective experiences (Yin, 2017). In harmony with this, case study research tends to account for various contextual factors simultaneously.

"Southern Ontario University" (SOU hereafter) is the pseudonym for a large, research-oriented university in Canada. According to its website, approximately 50,000 students, undergraduate and graduate combined, attended the university in 2019. SOU hosted more than 6,000 international students from over 150 countries in 2019 and had exchange agreements with over 80 international partner universities. SOU offers pre-admission English language education through its language institute for multilingual international students who speak English as an additional language. Both locally and nationally, SOU is known for its multicultural and multilingual campus community, embodied by its notably diverse student population. SOU has two campuses in Ontario, each with its student residence which hosts both local and international students.

Three multilingual international students were recruited to participate in the study through an email invitation in the winter of 2019 (see Table 1). The email invitation was distributed with the assistance of the international student group at the university. Since this paper focuses on three theoretical perspectives, case studies of three participants were selected to differently illustrate and contextualise the potential of each perspective. Twelve interviews were conducted as part of this case study: four with each participant. The interviews lasted approximately 60 minutes and were semi-structured. Richards (2009) explained the affordance of semi-structured interviews by saying that:

the interviewer has a clear picture of the topics that need to be covered (and perhaps even a preferred order for these) but is prepared to allow the interview to develop in unexpected directions where these open up important new areas. (p. 186)

General interview topics included but were not limited to, academics, social life, language use, Canadian culture, psychological and physical well-being, spirituality and religion, finances, and work experience. Data analyzed consisted of a multiphase process. Interviews were transcribed, read multiple times, and aggregated into categories based on common themes (Gbrich, 2007) that related to the focus on identity. All identifying information has been anonymized. 
Table 1

Information on Participants

\begin{tabular}{|c|c|c|c|c|c|}
\hline $\begin{array}{l}\text { Participant } \\
\text { (pseudonym) }\end{array}$ & $\begin{array}{c}\text { Gender and } \\
\text { age }\end{array}$ & $\begin{array}{l}\text { Multilingual } \\
\text { repertoire }\end{array}$ & $\begin{array}{l}\text { Academic level } \\
\text { and program }\end{array}$ & $\begin{array}{l}\text { Place of } \\
\text { origin }\end{array}$ & $\begin{array}{l}\text { Length of } \\
\text { time at SOU } \\
\text { at time of } \\
\text { study }\end{array}$ \\
\hline Pablo & Male, 22 & $\begin{array}{c}\text { Spanish, } \\
\text { English, } \\
\text { Portuguese, } \\
\text { French, ASL }\end{array}$ & $\begin{array}{l}\text { Undergraduate, BA } \\
\text { with honours in } \\
\text { criminology }\end{array}$ & Colombia & $\begin{array}{l}\text { Three and a } \\
\text { half years }\end{array}$ \\
\hline Sabrina & Female, 31 & $\begin{array}{l}\text { Portuguese, } \\
\text { English, French, } \\
\text { Italian, Spanish }\end{array}$ & $\begin{array}{l}\text { Graduate, Master } \\
\text { of Business } \\
\text { Administration } \\
\text { (MBA) }\end{array}$ & Brazil & Four months \\
\hline Seth & Male, 24 & $\begin{array}{l}\text { Cantonese, } \\
\text { English, } \\
\text { Mandarin } \\
\end{array}$ & $\begin{array}{l}\text { Undergraduate, BA } \\
\text { in linguistics }\end{array}$ & Macau & Four months \\
\hline
\end{tabular}

Over the next several paragraphs, each theoretical perspective will be presented individually. The first perspective examines the influence of the culture, in its broadest sense, on Seth's identity experiences as he navigated his international journey in the United States and Canada. The second one considers how membership in social groups, which are created socially on the basis of a common category, impacted Sabrina's identity construction as someone who was positioned as an ESL speaker in Canada. The last perspective on identity draws on post-structuralist approaches which view identity in the plural sense and as primarily a product of discursive practices embedded in political contexts.

\section{SETH: IDENTITY AND CULTURE}

In terms of identity, cultural psychology is concerned with the role culture plays in the process of one's identity construction and enactment. Two individuals who grow up in two different cultural environments are expected to behave, think, and feel differently from each other (Markus \& Kitayama, 2003). While such a difference should not be the product of culture alone, cultural psychology considers how and to what extent cultural "systems" contribute to that variation. Integrating perspectives from cultural psychology in theorising international student identity is important because experiences of transnationalism, such as studying abroad, can and often have the potential to cause identity conflict based on different cultural values. Much of the early culture-oriented research into international students' experiences in higher education has concentrated on culture shock, particularly by comparing cross-cultural collective behaviour between international students' sending and hosting countries (e.g., Chapdelaine \& Alexitch, 2004; Hamboyan \& Bryan, 1995; Lewthwaite, 1996).

One seminal framework for understanding the influence of culture on the individual is that of construals of the self. Construals are patterns of behaviour (Markus \& Kitayama, 2003) encapsulated in "two broad modes of being - an independent self-construal and an interdependent self-construal" (p. 280). Through the independent construal, one's behaviour and sense of self are defined by "one's own internal repertoire of thoughts, feelings, and actions" (Markus \& Kitayama, 1991, p. 226). On the other hand, through the interdependent construal, one's behaviour is "determined, contingent on, and, to a large extent organized by what the actor perceives to be the thoughts, feelings, and actions of others in the relationship" (Markus 
\& Kitayama, 1991, p. 227). Construals of the self thus shed light on the potential impact culture can have on the ways one ascribes value to and sees the self, the other, and the relationship between the two. The independent and interdependent construals are primarily discussed in contexts of collectivist and individualist societies (Triandis, 2018).

Previous research offers interesting insight into how cultural differences may impact the identity of an international student. Nevertheless, in such research contexts, the focus tends to be on a specific component of the academic experience, thereby positioning identity more peripherally (Choi, 2015; Jackson, 2002). Furthermore, there is considerable discussion about how international students' sense of self is affected by cultural differences in higher education, but a theory of identity is not always in place (e.g., Lee, 2009; Wang, 2012). For international students learning in an additional language, proficiency in the language of instruction contributes immensely to how international students demonstrate their knowledge and enact their identities in the classroom; however, language is rarely the sole factor (Tavares, 2019). Sociological factors whose regard may vary from culture to culture, such as race, ethnicity, gender, sexuality, and age, in addition to (conflicting) behavioural differences between individualist and collectivist societies, particularly when manifested in the academic classroom, can lead to international students feeling excluded or inferior in relation to their local peers (Tatar, 2005; Tavares, 2016; Xing \& Bolden, 2020).

Herein, the identity-related experiences of Seth are theorized through the framework of construals of the self. Prior to beginning his academic studies in Canada, Seth had studied in the United States first as a high school student in New York, and second as a college student in California. Consequently, he had gained extensive exposure to cross-cultural experiences. When Seth began his studies in New York as a teenager, he was linguistically and academically unprepared for the demands of his high school. Yet, Seth's greatest challenge was cultural in nature. A sense of community was important for his emotional wellbeing. However, the competitive and individualist behaviour characterising peer relationships and the social environment of his new school caused him much internal conflict for it only methodically diverted him from the possibility to meaningfully connect with others. He observed, for instance, that asserting one's position spiritedly over someone else's in the shared space of the classroom evoked approval and recognition from others. In that particular community, standing out was linked to individual academic success, and he felt the pressure to act similarly as a way to embody that kind of identity, though this was not his intrinsic inclination.

Outside the school, Seth believed that New Yorkers generally prioritized autonomy, privacy, and formality. Seth's unexpectedly brief social experiences with New Yorkers only resulted in him feeling less like his envisioned self. He wished to be part of a social group, but described inland New Yorkers as "closed off." Fueled by the need to practice his language as well as form new relationships, he was disappointed when his casual conversational attempts with locals were experienced awkwardly by his interlocutors. When juxtaposed with his gregarious personality and desire to relate, Seth's continuously formulaic interactions with locals left him feeling out of place for three years. Despite having the chance to meet many others during such a long journey, none of these connections organically evolved into a deep and longlasting friendship. It was only when Seth moved to California for college that he experienced significant progress in his social life. In fact, his social life in California was the complete opposite of that which he had had in New York. He believed that the "nicer" weather was the sole reason behind Californians' apparent openness to socialise with newcomers. 
In college, Seth made new friends and the active social network he was then embedded in contributed directly to his feeling of belonging. In his interviews, Seth would never refer to any of his acquaintances from New York as friends. In discussing his experiences in California, conversely, many of the people he referred to were mentioned as "my friends (from Cali)." He described the college as "very small" and explained that international and local students interacted together with ease. These two contextual factors afforded him access to a community with which he identified more, especially since he shared many individual interests with his peers in the computer science program. Today, what Seth missed the most about his time in California was going to the beach and playing sports with friends. When Seth moved from California to study at SOU in Canada, he felt as if all progress had been lost. He did not know any locals in the community surrounding SOU, and after a few weeks of "feeling out" the new place, he considered the new Canadian city gray and uninviting. Local Canadians-like New Yorkers-were for him boring and reticent. He explained:

I just kind of like west coast better. I'm kind of more like a[n] outgoing person. And [Canadian city] [is] more like east coast, people are more... conservative. I think of the east coast like that. When I was in New York, people were more like, sort of checked out, just not as open as like, in the west coast. You can easy make friends [on the west coast], very easily. Yeah, and people just less judge [you]. That's why. The weather is always so nice. Actually, I miss it so much.

Now in the present time, Seth defined himself as more culturally western-oriented as a result of his complex cross-cultural experiences. He explained: "I've been living in a western society for too long, I'm kind of like a mix, so I don't have strong, like, east opinions, east perspectives... [but] more west perspectives." Considering Seth's identity-related experiences in terms of construals of the self provides insight into how the cultural set-up of his communities in the United States and Canada interacted with his view of himself. Indeed, the focus within the framework lays upon the person rather than on the place. We might argue, for example, that Seth felt like himself more fully in California when he was part of a community. However, New York and California may still be considered individualist societies in general (though subcultures may function differently), so the emphasis returns to be on the individual. Most importantly, after almost seven years in the United States, Seth may have experienced a shift in his construal: "I'm kind of like a mix," meaning that he came to adopt some of the cultural values and practices of the host society, while simultaneously retaining others from his upbringing.

Seth's "more western perspectives" also caused him conflict with other students from Macau whom he met along the way. He explained that his ways of seeing the world often clashed with those from his peers from Macau, saying explicitly that he was "just too different" now. Additionally, he refused to invest time into potential friendships with those he believed he could not come to culturally relate to. He saw these investments as threats to the self-development he had experienced and preferred to avoid situations in which his new "mixed" orientation might bring his new identity into question. Including the cultural context into an exploration of an international student's experience therefore affords us the chance to account for how different cultural systems impact the individual in regard to emotion, cognition, and the desire to act. It also allows us to consider how and to what extent one's well-being may be interconnected with acculturation for different individuals - the more conflicting the local values may be, the more disconnected one may feel from their perceived or hoped-for self.

Of course, construals of the self is by nature a broad framework to study the influence of culture on the individual through two divergent modes of being. Needless to say, individual variation from the prescribed 
collective behaviour will always exist to reflect diversity at the individual level. By examining identity from a cultural perspective, the individual is not conceptualized as lacking an individual identity. Much to the contrary, individuals are seen as agents, though agency is exercised differently (Markus \& Kitayama, 1991). Nevertheless, the individual is always embedded in a specific cultural context which, in turn, affects how important others become for one's understanding of themselves. In Markus and Kitayama's (1991) words, what people "believe about the relationship between the self and others and, especially, the degree to which they see themselves as separate from others or as connected with others" (p. 226, italics in original) can result in markedly distinct implications for one's cognitive, emotional, and motivational experiences.

\section{SABRINA: IDENTITY THROUGH SOCIAL GROUPS}

Stemming from social psychology, social identity theory looks at how identity is influenced by group membership. From such a perspective, society is composed of social groups, which are based on a diverse range of categorizations, such as racial, ethnic, linguistic, and so on. Pioneered by Henri Tajfel and John Turner throughout the $70 \mathrm{~s}$, social identity theory proposes that when individuals from different social groups interact, they act as representatives of their respective groups, and when doing so, the individual's identity is thus derived "from the social categories to which [the individual] belongs" (Hornsey, 2008, p. 206). Although an individual belongs to several groups simultaneously, each group will produce a distinct social identity for the individual (Hogg et al., 1995). The interactional context wherein the individual member is embedded will affect which social identity becomes more salient at a given time and place, therefore making social identities dynamic. Between individual and group identities, the group one takes precedence and becomes prescriptive of how the group member should act, think, and feel. Group-specific stereotypes play a major role in enforcing boundaries between groups (Hogg et al., 1995).

The enactment of a social identity through group membership may occur through a process called depersonalization. Despite the name, depersonalization is not the erasure of the individual, but "a contextual change in the level of identity (from unique individual to group member)" (Hogg et al., 1995, p. 261), rendering individual identity less relevant. The notion of self-categorization (Turner, 1985), which includes the process of depersonalization, proposes that prototypes govern people's representations of social groups. Hogg and colleagues (1995) defined a prototype as "a subjective representation of the defining attributes (e.g., beliefs, attitudes, behaviors) of a social category" (p. 261). Prototypes can be based on actual people who most fully represent the group or on the "ideal" member, conceptualised upon a sum of general, positive features (Hogg et al., 1995). In-group members evaluate themselves and those from the outgroup by comparing oneself and the other with the prototype. Prototypes are highly responsive to contextual changes and reflect the dynamic nature of group interaction, that is, they change according to the outgroup in question.

Paying attention to the individual as someone who functions within a larger social group helps us understand why individual members behave the way they do. In other words, by studying the group, we learn about the individual and by studying the individual, we learn about the group. Examining international student identity from a social identity theory perspective is relevant in relation to at least two obvious and often interrelated categorizations: the institutional and the linguistic. A student arriving from overseas will be automatically grouped into the "international" or "foreign" student group. In comparison with their "domestic" or "local" peer groups, for example, international students tend to face more discrimination on the basis of their institutional status (Charles-Toussaint \& Crowson, 2010; Lee \& Rice, 2007), which is 
constructed through and maintained by a set of negative stereotypes that differentiate them from the "domestic students" group (Heng, 2018). Stereotypes may be reinforced by social, educational, and institutional practices extended differently to each group. Being in the marked group will therefore affect the members' identity-related experiences in complex ways.

The second categorization for international students is linguistic in nature, and often goes hand-in-hand with the institutional. To illustrate, in Canada, the vast majority of international students in higher education are multilingual learners for whom English is not a first language (Canadian Bureau of International Education, 2019). In light of language alone, students are divided as either native speakers or non-native speakers; the latter commonly referred to as English as a second language (ESL) students. In this juxtaposition, the non-native group remains the marked one, whose collective identity is also linked to specific stereotypes which tend to conflate non-native proficiency with inferiority and deficit (Marshall, 2009). Students who speak English as an additional language routinely have to resist the material ramifications of the prevailing assumption that they cannot succeed academically because of their language. Because language difference is seen as a form of deficit, the legitimacy of the identity of the group is never fully solidified and is subject to much lexical experimentation, varying from LEP (Limited English Proficiency) students (Shapiro, 2014) to the widespread ESL and beyond (Tavares, 2020).

Sabrina was an international student whose identity was influenced directly by her group membership. Though Sabrina had studied English for years in Brazil before coming to Canada, following her first few weeks in the new environment, she concluded that her level of proficiency in the language was insufficient for what she desired: to communicate naturally and effortlessly with local Canadians. In particular, her oral language skills needed further practice, and her vocabulary was limited. Additionally, Sabrina held an undergraduate degree in journalism, but felt that her ability to demonstrate her expert knowledge was also constrained by her level of proficiency in the English language. She decided to enrol herself in English language courses at a private ESL school in order to improve her linguistic skills. However, as her journey as an ESL student proceeded, she grew increasingly dissatisfied with the overall experience. She did see improvement in her language, but she metaphorised her personal ESL student experience as if "living in a bubble" or in "the little international student world" wherein every interaction with the "real world" through the language program seemed programmed and superficial.

Sabrina defined one marker of the collective ESL student identity she experienced specifically on the basis of language proficiency. She explained that being an ESL student meant that "nobody spoke completely correct, but it was that feeling of not being judged." Language proficiency was central to differentiating the ESL from the native-speaker group: "Canadians always diffuse that kind of intimidation because they speak so well, natives speak so well, so automatically that intimidates you," she explained. Despite the feeling of comfort and safety that Sabrina experienced as an ESL student, she felt as though the pace of improvement was too slow and that she needed to be more intensively challenged in the language so as to live through her real potential. However, what caused her the most conflict was that her lived social experiences were becoming incrementally more incongruent with the ones she had envisioned for herself as an international student. She knew that she would be attending college or university in Canada sometime after the language program, contrary to the vast majority of her ESL peers who would be returning home immediately after the program's conclusion. Therefore, she needed to find a way to step out of the "ESL bubble" in preparation for an upcoming, different experience. 
Despite being a difficult decision, Sabrina opted to formally disconnect herself from the ESL school once she had completed her course. She still had another level to take before finalising her entire language program, but her association with the school progressed to eventually be the very means sustaining the social part of her ESL identity. Sabrina's identity-related experiences may be theorized through social identity theory by centering on her membership to the ESL student group. Her insufficient proficiency in English upon her arrival in Canada led her to join a language school. Yet, alongside learning the language emerged an identity which she had not anticipated, but enacted fully in the beginning as it afforded her the chance to meet her immediate needs. In the context of her personal experience, the prototype of the ESL student group was someone who spoke English incorrectly, interacted limitedly with Canadian society, and remained primarily within the group. Sabrina gradually deviated from the prototype as her individual identity needs gained priority but conflicted with those of her group identity. Moreover, the ways in which she perceived to be judged by outgroup members - i.e., by native speaker Canadians - fueled her desire and acceptance to be less like her ingroup members.

In joining the ESL group, Sabrina's identity at the individual level was qualitatively minimised. Other roles, skills, interests, and abilities that constituted her identity became irrelevant to her social group and collective experiences. Social identity theory focuses primarily on the importance of group membership for one's positive sense of self. However, Sabrina's case might suggest that this (beneficial) feeling can also be temporary. While the theory continues to be expanded today, the assumption that one's self-definition is extracted principally from one's collective identity was one of its original shortcomings (Hornsey, 2008). Hornsey (2008) has argued that the theory has evolved to recognise that "individuals and groups mutually influence each other" and that group norms can be "actively contested, discussed, and shaped by individuals" (p. 216). Indeed, Sabrina's own experiences illustrate these (re)actions in context and suggest that individual group members' behaviours can help challenge our assumptions about the group as an invariable entity.

\section{PABLO: NEGOTIATING MULTIPLE IDENTITIES}

Poststructuralist approaches to the construct of identity tend to reject notions that manifestations of identity remain static, singular, exclusive, and coherently organised across the lifespan. Duff (2012) explained that poststructuralism is "an approach to research that questions fixed categories or structures, oppositional binaries, closed systems, and stable-truths and embraces seeming contradictions" (p. 412). Essentially, poststructuralism holds skepticism toward metanarratives and considers identity to be largely a product of a discursive process embedded in complex political, social, and cultural contexts (Han, 2011). The boundaries between identity categories are blurred, unlike in social identity theory, and may evolve over time, thus forming "a dynamic and shifting nexus of multiple subject positions, or identity options, such as mother, accountant, heterosexual, or Latina" (Pavlenko \& Blackledge, 2004, p. 35). Viewed as contextually and discursively shaped, identities may be imposed, resisted, or claimed by the individualidentity is primarily something one does. Social interaction typically becomes the "common ground" on which identities are (simultaneously) indexed.

By focusing on language in interaction, Koehne (2005) illustrated the many positions international students may simultaneously occupy, at times even contradictorily. The students' storylines revealed how cultural hybridity in international higher education mobility afforded the students "the space to speak themselves as a different person" (p. 114, italics added). This "space" was one where the students could 
reinvent themselves by claiming new positionings, but wherein they also had to resist imposed identities of otherness in the host environment. Similarly, Wang (2020) investigated how Asian teaching assistants (TAs) monitored their English language to re-position themselves as more legitimate instructors at a university in the United States. Since having an accent and tone were markers of professional identity illegitimacy, the TAs worked to model their language to sound more native-like in order to avoid marginalization and gain acceptance from students. In general, a student's sense of legitimacy and of competency in higher education are constructed around eloquent language. Multilingual international students who do not perform linguistically like their native speakers are thus often considered less competent by their local peers (Yoon, 2013).

When Pablo began his first year of studies at SOU, he was unfamiliar with the culture and the register of language used in Canadian academe. For all of first year, he feared that he would be unable to perform like local, native-speaker students, who had grown up in Canada and consequently had much more exposure to the local education system. To cope, Pablo introduced himself to his instructors in first year explicitly as an international, ESL student as he believed that such labels would help contextualise his academic performance in case it grew to be unsatisfactory. Yet at the same time, he wished to meet local students to expand his cultural and linguistic repertoire. One of his first-year lectures had a tutorial attached to it, divided into two sessions: one for ESL and one for non-ESL students. Pablo signed up for the latter so that his chances to socialise with locals might be better, especially because the small size of tutorial sessions allowed students to familiarise themselves with one another more naturally. Thus, for much of first year, Pablo cleverly embraced and occupied two seemingly contradictory identity positions. Each of them consisted of a specific audience, and therefore, different possibilities for his future.

Concurrent to his academic journey at the time was the broadcasting of a show titled "Narcos" on Netflix. The series took place in Colombia-Pablo's home country-and presented the investigation into the life of a Colombian drug lord who coordinated major illegal drug trafficking. The stereotypes perpetuated by the series, such as those of Colombia being a society marked by poverty, violence, drug traffic, and corruption, directly impacted Pablo's identity in interaction. Many of his classmates would approach him to "confirm" these stereotypes, covertly positioning Pablo as a spokesperson whom he did not wish or have to be. Confronting these stereotypes and resisting association or the superimposition of them upon his individual self was a laborious and vexatious task for Pablo. He commented very emotionally on this experience by criticising not the show itself, but the far-reaching effect it had, to the point of materialising fiction into his lived experiences:

I hate it. I hate it when everyone talks to me about Narcos. 'Cause they're like: where are you from? And I'm like: Colombia, and they're like: oh, Narcos. I'm like, yeah, sure. I hate it, I hate it. When I came here in first year, that was the boom: Narcos. People think that's how Colombia looks like. That is how we all live, we don't have any cities or cars.

Progression into his academic program and social life resulted in strong feelings of self-confidence for Pablo. In the third and fourth years of his BA program, his classes advanced from lecture to seminar-style. Smaller conversational classes afforded him more agency and control over the construction of his identityhe had more open "space" to do identity work - and in return, he permanently discarded the ESL identity which he had been stepping in and out of, mostly for precaution, during his first and second years. He was no longer an unknown student in the large lecture hall crowd, and because he could now be seen as an individual, consistency in self-presentation was key. As a result of this self-expansion, Pablo spoke as if he 
inhabited "two worlds": one which he inherited and one which he pieced together for himself through (the English) language. Despite the importance of this dual identity for him, they were not fixed and oscillated according to the surrounding context. "When I'm in English" suggests identity-related experiences that are transitory (in or out of English) but also unstable (when). Life in English consisted largely of friendships with other like-minded multilingual international students with whom he only spoke in English. English was not just a new language; it was also a new experience of selfhood:

I feel like English is my life. When I'm in English, I feel like it's my real life. And when I'm speaking Spanish, it's just like, a side. Like, my family and vacation and that's it. But like, my friends, like, everything to me now is English.

From a poststructuralist point of view, Pablo's identity may be (better) seen in the plural sense, as in a dynamic collection of intersecting experiences and positions sustained primarily by language. He drew on language to self-ascribe two oppositional identities synchronically, each with its own set of perceived characteristic embodiments: ESL if unsuccessful academically, and non-ESL when successful socially. His dual identity position exposed the artificiality with which the institution created the ESL label for him as a multilingual individual. This position was thus not static, but variably situated. As Gee (1999) put it, there are "multiple identities we take on in different practices and contexts" (p. 39), depending on what is at stake and whom our interlocutors may be. Moreover, some of Pablo's identities competed with one another. Such was the case when he spoke English and Spanish. However, speaking Spanish evoked a seemingly less significant identity. He considered it to be just a "side," although one which he could not completely dismiss. Nevertheless, it was accompanied by specific experiences (i.e. family and vacation) that were not part of his "English" world.

Like any other theory, poststructuralist perspectives to identity are not without criticism. Block (2013) calls for more attention toward the psychological processes of identity formation. In alignment with other authors, Block rejects the notion that selfhood is a product of social interaction alone and suggests that psychoanalytic orientations should be combined with social ones so that identity may be viewed "as fluid and unstable, not just as a response to an ever-changing environment but also as an effect of emotions" (p. 21). This means that psychological characteristics unique to an individual should be taken into consideration. When viewing identity as a discursive construction, Haugh (2008) cautions that the collaborative process by which identities are defined in interaction needs to be made more explicit. He argues that poststructuralist traditions often proceed as if "what international students say can be equated with their identities, without critical attention being paid to the way in which identities emerge as a conjoint construct through interaction" (p. 207, italics in original). In short, he states that the actual discursive negotiation of identities by interlocutors needs to be clearly articulated.

\section{DISCUSSION AND CONCLUSION}

Construals of the self, social identity theory, and poststructuralist perspectives help culturally, socially, and linguistically/politically situate international student identity construction, respectively. All three perspectives coherently consider the context in which international students may be embedded and reveal its interplay with international students' lived experiences. However, the prevailing discourse that shapes international student identity unfavourably does so because it greatly dismisses the context. Without paying critical attention to context(s), identity is seen as static and as a choice of the individual completely, and from there, overgeneralizations follow automatically. Thus, the role played by the sociocultural context 
may be seen as the most salient theoretical theme among all three perspectives. At the same time that these perspectives allow us to explore and account for some of the cultural, social, and linguistic processes encircling international student identity construction, they do not position international students merely as products of their environments. On the contrary, they recognise individual agency to varying extents and purposes.

Agency is therefore approached differently, as each case illustrates. Construals of the self as a theory is concerned with how cultural systems influence the psychological development of an individual into two modes of being: namely the individualist and the collectivist. Consequently, the self experiences conflict when navigating a cultural environment where the "opposite" construal is in place. This was precisely the case for Seth. Yet, Seth's identity changed and expanded to reflect his experience as a transnational. This may also speak to the notion of whether one is either fully an individualist or a collectivist. On the other hand, social identity theory considers how group memberships impact the individual. These memberships, often based on common categorizations, still vary from place to place as societies ascribe value to these categories contrastingly. As a newly arrived student, Sabrina met many of her initial needs by joining a community formed on the basis of language. Because her school failed to connect her meaningfully with the host society, she saw her potential gains constrained by the ESL student experience specific of the group she joined. After some time, Sabrina left the school to actively search for new communities.

Differently, poststructuralist perspectives tend to focus on the multiple and intersecting identities of the individual and how these emerge in interactions wherein power at play needs to be more explicitly examined. Pablo was positioned by others, but also resisted and re-positioned himself creatively as he increasingly acquired the means to do so. These similar insights from all three perspectives link the theories together around the dynamic nature of identity. Of course, as the cases suggest, identity being dynamic is relative to each theoretical perspective. At another level, all three students demonstrated awareness, from their immediate lived or perceived experiences in their host environments, of the international student identity being one of an outsider. This is not a surprise considering the very title "international student" implies a kind of foreignized identity. However, each theoretical perspective contextualized the unique ways by which such exclusions occurred. When analyzed from all three perspectives, the students' experiences suggest that the educational environments to which the students belonged were culturally inflexible. Their monocultural orientations may then be seen as the very force behind the construction of an othered identity, which cannot exist naturally, but only as a consequence of dominant institutional cultures. The theories help look at this construction from different angles.

Consideration of international student identity as a complex and situated experience better allows for international student individual agency. Put differently, identity homogenization stands in conflict with individual agency because it favours a group-based view of the individual that is simplistic and contextualized by collective rather than individual patterns of development. All three theoretical perspectives illustrate possibilities of individual agency by focusing on the students' choices of what to invest in, culturally, socially, and linguistically/politically speaking. The students' investments may be seen as those toward the "collective:" refusing to take part in cultural experiences, to join or leave social groups, and to (re)invent the self through new language. These would be experiences or interactions in which the identity of the group overrides that of the student, thus hindering individual progress that is meaningful to the self. In terms of supporting international student agency, members of the host academic community, including but not limited to faculty, support staff, and local students, should therefore avoid the "tendency 
to homogenize" (Malcolm \& Mendoza, 2014, p. 595) and the tendency to focus on deficit. Moreover, a critical evaluation of the institutional environment continues to be necessary for international student success.

In closing, all three perspectives have their own conceptual and methodological limitations, discussed extensively in the literature already. Most importantly, each perspective focuses separately on distinct dimensions of identity (e.g., cultural, social, linguistic) and on the specific processes therein. For this reason, while the concern remained the same throughout this paper-that is, on international student identity - these theoretical perspectives are not interchangeable and should be evaluated in their own right. Jointly or individually, these perspectives can contribute to a systematic exploration of the influence of the context and of the agentive nature of international students in relation to their identity-related experiences.

Vander Tavares, Ph.D., is currently a post-doctoral research fellow in the Faculty of Education at
Høgskolen i Innlandet (Inland Norway University of Applied Sciences). His major research interests
include internationalisation of higher education and the international student experience, the
relationship between language, culture, and identity, and second language acquisition. He is the editor
of Multidisciplinary Perspectives on International Student Experience in Canadian Higher Education
(IGI Global) and the author of International Students in Higher Education: Language, Identity and
Experience from a Holistic Perspective (Lexington Books). Email: vanderjuniort1@gmail.com.

\section{REFERENCES}

Abdelal, R., Herrera, Y. M., Johnston, A. I., \& McDermott, R. (2006). Identity as a variable. Perspectives on Politics, $4(4), 695-711$.

Block, D. (2013). Issues in language and identity research in applied linguistics. ELIA: Estudios de Lingüistica Inglesa Aplicada, (13), 11-46.

Campbell, C. G. (2017). Navigating my Blackness: An Afro-Caribbean international student experience. The Vermont Connection, 38(1), 42-50.

Canadian Bureau of International Education. (2020). International students in Canada continue to grow in 2019. Retrieved from https://cbie.ca/international-students-in-canada-continue-to-grow-in-2019/

Chapdelaine, R. F., \& Alexitch, L. R. (2004). Social skills difficulty: Model of culture shock for international graduate students. Journal of College Student Development, 45(2), 167-184. DOI: https://doi.org/10.1353/csd.2004.0021

Charles-Toussaint, G. C., \& Crowson, H. M. (2010). Prejudice against international students: The role of threat perceptions and authoritarian dispositions in US students. The Journal of Psychology, 144(5), 413-428. https://doi.org/10.1080/00223980.2010.496643

Choi, J. Y. (2015). Reasons for silence: A case study of two Korean students at a US graduate school. TESOL Journal, 6(3), 579-596. https://doi.org/10.1002/tesj.209

Creswell, J. W., \& Poth, C. N. (2016). Qualitative inquiry and research design: Choosing among five approaches. Sage Publications.

Duff, P. (2012). Issues of identity. In S. Gass \& A. Mackey (Eds.), The Routledge handbook of second language acquisition (pp. 410-426). Routledge.

Gargano, T. (2012). Grounded identities, transient lives: The emergence of international student voices in an era of cosmopolitan learning. Journal of International Students, 2(2), 144- 156.

Gee, J. P. (1999). Introduction to discourse analysis. Routledge.

Gerring, J. (2007). Case study research: principles and practices. Cambridge University Press. 
Gbrich, C. (2007). Qualitative data analysis: An introduction. Sage Publications.

Hamboyan, H., \& Bryan, A. K. (1995). International students. Culture shock can affect the health of students from abroad. Canadian Family Physician, 41, 1713-1716.

Han, S. (2011). The fragmentation of identity: Post-structuralist and post-modern theories. In A. Elliot (Ed.), Handbook of Identity Studies (pp. 83-99). Routledge.

Haugh, M. (2008). The discursive negotiation of international student identities. Discourse: Studies in the Cultural Politics of Education, 29(2), 207-222. DOI: 10.1080/01596300801966849

Heng, T. T. (2018). Different is not deficient: Contradicting stereotypes of Chinese international students in US higher education. Studies in Higher Education, 43(1), 22-36. doi: 10.1080/03075079.2016.1152466

Hogg, M. A., Terry, D. J., \& White, K. M. (1995). A tale of two theories: A critical comparison of identity theory with social identity theory. Social Psychology Quarterly, 58(4), 255-269.

Hornsey, M. J. (2008). Social identity theory and self-categorization theory: A historical review. Social and Personality Psychology Compass, 2(1), 204-222.

Jackson, J. (2002). Reticence in second language case discussions: Anxiety and aspirations. System, 30, 65-84. doi:10.1016/S0346-251X(01)00051-3

Koehne, N. (2005). (Re)construction: Ways international students talk about their identity. Australian Journal of Education, 49(1), 104-119.

Lee, G. (2009). Speaking up: Six Korean students' oral participation in class discussions in US graduate seminars. English for Specific Purposes, 28(3), 142-156. https://doi.org/10.1016/j.esp.2009.01.007

Lee, J. J., \& Rice, C. (2007). Welcome to America? International student perceptions of discrimination. Higher Education, 53(3), 381-409. doi: 10.1007/s10734-005-4508-3

Lewthwaite, M. (1996). A study of international students' perspectives on cross-cultural adaptation. International Journal for the Advancement of Counselling, 19(2), 167-185.

Li, Y. (2004). Learning to live and study in Canada: Stories of four EFL learners from China. TESL Canada Journal, $22(2), 25-43$.

Malcolm, Z. T., \& Mendoza, P. (2014). Afro-Caribbean international students' ethnic identity development: Fluidity, intersectionality, agency, and performativity. Journal of College Student Development, 55(6), 595-614. https://doi.org/10.1353/csd.2014.0053

Markus, H. R., \& Kitayama, S. (1991). Culture and the self: Implications for cognition, emotion, and motivation. Psychological Review, 98(2), 224.

Markus, H. R., \& Kitayama, S. (2003). Culture, self, and the reality of the social. Psychological Inquiry, 14(3-4), 277283. doi: 10.1080/1047840X.2003.9682893

Marshall, S. (2009). Re-becoming ESL: Multilingual university students and a deficit identity. Language and Education, 24(1), 41-56. https://doi.org/10.1080/09500780903194044

Pavlenko, A., \& Blackledge, A. (Eds.). (2004). Negotiation of identities in multilingual contexts. Multilingual Matters.

Popadiuk, N., \& Arthur, N. (2004). Counseling international students in Canadian schools. International Journal for the Advancement of Counselling, 26(2), 125-145.

Richards, K. (2009). Interviews. In J. Heigham \& R. Croker (Eds.), Qualitative research in applied linguistics: A practical introduction (pp. 182-199). Palgrave MacMillan.

Ryan, J. (2011). Teaching and learning for international students: Towards a transcultural approach. Teachers and Teaching, 17(6), 631-648. https://doi.org/10.1080/13540602.2011.625138

Ryan, J., \& Carroll, J. (2007). 'Canaries in the coalmine': International students in Western universities. In J. Ryan \& J. Carroll (Eds.), Teaching international students (pp. 3-10). Routledge.

Sawir, E., Marginson, S., Deumert, A., Nyland, C., \& Ramia, G. (2008). Loneliness and international students: An Australian study. Journal of Studies in International Education, 12(2), 148-180. doi: $10.1177 / 1028315307299699$ 
Shapiro, S. (2014). "Words that you said got bigger": English language learners' lived experiences of deficit discourse. Research in the Teaching of English, 48(4), 386.

Skyrme, G. (2007). Entering the university: The differentiated experience of two Chinese international students in a New Zealand university. Studies in Higher Education, 32(3), 357372. DOI: 10.1080/03075070701346915

Tatar, S. (2005). Classroom participation by international students: The case of Turkish graduate students. Journal of Studies in International Education, 9(4), 337-355.

Tavares, V. (2016). The role of peer interaction and second language learning for ESL students in academic contexts: An extended literature review [Unpublished master's thesis]. York University.

Tavares, V. (2019). A review of peer interaction and second language learning for ELL students in academic contexts. Canadian Journal for New Scholars in Education/Revue Canadienne des Jeunes Chercheures et Chercheurs en Éducation, 10(2), 113-121.

Tavares, V. (2020). International students in higher education: Language, identity and experience from a holistic perspective [Unpublished doctoral dissertation]. York University.

Tian, M., \& Lowe, J. (2009). Existentialist internationalisation and the Chinese student experience in English universities. Compare, 39(5), 659-676. DOI: 10.1080/03057920903125693

Triandis, H. C. (2018). Individualism and collectivism. Routledge.

Turner, J. C. (1985). Social categorization and the self-concept: A social cognitive theory of group behaviour. In E. J. Lawler (Ed.), Advances in Group Processes: Theory and Research (2nd volume) (pp.77-122). JAI.

Wang, Y. (2012). Transformations of Chinese international students understood through a sense of wholeness. Teaching in Higher Education, 17(4), 359-370. https://doi.org/10.1080/13562517.2011.641004

Wang, H. (2020). Stereotyped English language use and identity in Asian teaching assistants: A poststructuralist perspective. RELC Journal, 51(2), 294-308. DOI: 10.177/0033688218815703

Xing, D., \& Bolden, B. (2020). Learning at half capacity: The academic acculturation reality experienced by Chinese international students. In V. Tavares (Ed.), Multidisciplinary perspectives on international student experience in Canadian higher education (pp. 41-61). IGI Global.

Yin, R. K. (2017). Case study research and applications: Design and methods. Sage Publications.

Yoon, H. J. (2013). Challenging the "non-native English speaker" identity in US higher education: A case of international graduate students. Working Papers in Educational Linguistics (WPEL), 28(2), 55-75.

Zhang, Z. (2011). A nested model of academic writing approaches: Chinese international graduate students' views of English academic writing. Language and Literacy, 13(1), 39-59. 